\title{
The Perverse Rise of Sexual Orientation Identity Conflict in the Neo Liberal Order: A Critical Perspective
}

\author{
Edmund Obomanu, Luke Amadi \\ Department of Political and Administrative Studies, University of Port Harcourt, Nigeria
}

\begin{abstract}
This article is a critique of sexual orientation identity conflict in the neo liberal order. It explored evidence of perverse homophobic attacks on the Lesbians, Gays, Bisexual, Transgender, Queer and Intersexed persons -LGBTQIs in the United States by non LGBTQIs and argues that the liberal order has been unable to sustainably resolve sexual orientation identity conflict. The data derive from extensive fieldwork in the United States, which at the same time helps to illuminate recent broader issues and on the ground evidence associated with sexual identity conflicts. This included direct personal interviews and virtual online surveys on adult males and females between the ages of 25 to 50 among the gay and non-gay communities in New York City, Florida and California. It involved LGBT based NGOs, LGBT movements and Community Based Organizations (CBOs), Christians and non-Christians .Majority of the participants (75\%) were drawn from (CBOs) and 25\% from LGBT based NGOs and movements. Participants were deployed between August 1999 and January 2000, supplementary interviews were conducted between September 2014 and December 2015. Relational content analysis (RCA) was deployed to review secondary data including a longitudinal internet report that covered a three decade period (1990-2015). Additional evidence in the literature on related scenarios on the conflict in most states were utilized. The study concludes that "systemic sexual orientation identity conflict" has been endemic and had taken perverse and strategic turn at the post same sex marriage legalization. Based on our field experience, the article suggests the inevitability of novel policy response for resolution of the conflicts.
\end{abstract}

Keywords: Sexuality Identity Conflict, Green Sexuality, State Policy, Conflict Resolution

\section{INTRODUCTION}

Sexual orientation identity in the 21st century takes a novel turn both in Europe and America as liberal democracy seemingly becomes a universal construct. Recent trends in development studies point to poor critical exploration of the perverse sexual orientation identity conflict in most industrially advanced societies. Beyond this, the persistence of the conflict at post legalization of gay marriage in the United States in 2015, suggests the need for a novel policy response (Amadi and Wordu , 2016).

In Europe in places like France - despite repeated violent protests - a bill was passed in April 2013, on same sex marriage, thereafter in the month of May, popular French historian Dominique Venner, who was an anti-gay marriage protagonist, shot himself in the head in public place and died (Müser , 2012).

In Germany, Eva Henkel, member of the board of a pro- gay rights group, contends that in the opinion of the courts, there is insignificant difference between gay and heterosexual marriage (Müser, 2012). The Germany cabinet has a responsive gay Foreign Minister. Similarly, Berlin's Mayor notably removed himself from office ahead of his first election in 2001 proclaiming, himself to be gay and that "it is a good thing" (Müser, 2012:2).

In The Netherlands which was the first nation to organize official same-sex weddings in the world, Ames (2013) shows the incidence of intolerance, stating that despite legalization there is slow pace of same sex weddings taking place unlike heterosexuals.

On the contrary, in Russia in 2013, President Putin passed a law which foists a $\$ 3,000$ fine on advocates of gay and lesbian rights - encompassing gay marriage rights. With a 436-0 vote margin in the Duma, the Russian lower house of Parliament (Schofield, 2013).

Among scholars of development bend, the increasing contention on sexual identity results in conflicts which took divergent forms and deepened in the decade (Miller and Ryan, 2011). This has remained 
germane in contemporary social discourse. What this means to the future of human sexuality, social interactions and liberal democracy has been minimally studied.

Sex is a "determination made through the application of socially agreed upon biological criteria for classifying persons as females or males" (West and Zimmerman,1987, p.127). The American Institute of Medicine (IOM) (2011) argues that gender identity refers to the basic sense of being a man, a woman, or another gender (eg. transgender or gender queer - a rejection of the binary classification of gender). Sexual orientation identity conflict involves the incompatibility of sexual goals between persons of either same sex or opposite sexes or varying sexual orientations.

This study is concerned with the incompatibility of sexual goals between LGBTs and non-LGBTs. The understanding of sexual orientation conflict requires an evaluation of the fundamental triggers of the conflict such as the non LGBTs who conceive the LGBTs as violating heteronormative rules and contravening gender and sexual roles. Such social problem perhaps accounts for the recent rise in homophobic attacks.

Sexual orientation conflict goes beyond discrimination of the LGBTQIs and takes into account all sexually induced dissonance involving both non LGBTQIs against LGBTQIs or the later amongst themselves. It involves heterosexual relationships- couples, sex workers and their partners and similar sexually motivated disputes. It takes several forms such as verbal or physical assaults on the basis of gender (male or female), targeted attacks on basis of sexual orientation- lesbians, gay, bisexual, transgender, queer and intersexed individuals (LGBTQIs), violent sexual inclinations as in the case of rape and similar sexual violence. It also encompasses intimate partner violence (IPV) (Storey and Strand, 2012; Dutton and White, 2013).

The liberal order emerged at the end of the Cold War and triumph of capitalism in 1989. Long before the end of the Cold War, sexual identity has been at issue in scholarly discourse. Stuart Hall and du Gay (1996), argue that identity must be conceptualized as the relationship between subjects and broader discursive practices. As one of the most widely employed terms in the neo liberal theory, sexuality has become a contentious term within several sectors and academic disciplines. What stands the neo liberal order out is the liberating currents of democratization which results in resurgent sexuality movements pushing for legal status for SSM in the particular context of human rights. While on the other hand are opposing movements with implicit objection to such inclinations as violation of gender and sexual roles.

Sexual orientation conflict though a new field of inquiry was given a scholarly attention in recent decades following the 9th and 10th May, 2005 international sexual conflict conference in London. Although the conference looked at sexual conflict from biological perspective largely linked to conflicts on basis of number of children or how to raise children and mating by couples largely described as 'inter and intra locus conflicts"(Tregenza, et al;2006).

The intense controversy swirling around sexual orientation identity is reflective of the resurgent controversy and debates over the social, political and moral utility of the neo liberal theory at large. This increasing contention has reinforced the novel stance of neoliberal theorists redefining sexuality within the ambit of legalization exemplified in recent prognosis that defines "sexual rights" as "human rights" (UN, 2014).

Sexuality studies had emerged as a distinct field of inquiry and have moved from the margins to the center of scholarly debates and accounts for modes of sexual orientation identity of individuals and attendant implications. In popular media and social circles including the new media, sexuality has been among issues of wider global concern. This has resulted in mythical rhetoric and divergent perspectives to the study and understanding of sexuality.

In a cognitive research, Jeremy Redford and Aimee Van Wagenen (2011) tested the understanding and reaction of respondents to a survey item that assessed sexual orientation identity among American adults ages 65 and older. Their findings suggest the understanding of the respondents on issues of sexual orientation identity, however they recommended that the study is subject to further research.

The resurgent sexual orientation identity conflict has attracted recent global attention. In the United States, in 2006, National Statistics office set up the "Sexual Identity Project" to provide information on sexual identity (Haseldon and Joloza, 2009). On 30th April 2007, the government of the United States adopted the Equality Act (Sexual Orientation) Regulations 2007, to mitigate discrimination in the social life on the basis of sexual orientation. The U.S Senate passed a bill on hate crime in October 22, 2009, which was signed into law by President Barack Obama on October 28, 2009. 
Since the UN's 2014 resolution which defined sexual rights as human rights as explicated and the 2015 United States legalization of same sex marriage, resurgent sexual orientation conflict, stigmatization and resilience are perceptible and apt to explore. However, there is little or no debate over what is meant by sexual orientation identity conflict. The absence of a clear definitional consensus perhaps points to novel thinking linking sexual identity and conflict.

This article takes a new look at sexual orientation conflict. It will not seek to ignore the persistent targeted attacks on LGBTQIs by non LGBTQIs, discrimination and stigmatization, nor will it take up the argument -on the commemorative or pejorative perspectives of legalization of same sex marriage in the United States. Rather what it tries to argue is something more specific: that sexual orientation identity properly understood, is in crisis and has resulted in persistent conflicts in the neo liberal order. How such conflicting identity is affecting humanity is much more important to this paper.

The article acknowledges that a deep sexual orientation cannot easily fritter away but what viable options are available for a more inclusive and mutually beneficial transformation and importantly peaceful coexistence remains contentious. It makes the argument that sexual orientation identity conflict needs to be re-examined for the ways in which incompatibility of goals between the LGBTQIs and non LGBTQIs are affecting social harmony and peaceful co-existence. In particular, how the resurgent stigmatization at post SSM legalization is currently affecting both humanity and sexuality in the United States.

To critically explore these trends, the paper posits that policy makers, researchers similar stake holders- the LGBTQIs and non LGBTQIs communities, NGOs and CBOs, could come together for a novel re-evaluation of possible resolutions and strategies to contain the persistent sexual orientation identity conflict classified as hate crimes exemplified in homophobic attacks. This research argues that earlier studies on sexual orientation identity conflict in the neo liberal order have failed to critically provide such plausible insights surrounding the notion of sexuality which have resulted in persistent conflicts. Since evidence suggests that sexuality conflict often results in direct killing of human beings, which is both urgent and critical for policy re-evaluation, the article provides novel explorations that would enhance the theoretical basis of critical re-evaluation of the sexual orientation identity conflict. Such clearer research agenda is hugely significant to researchers, scholars, policy makers and new comers seeking for broader elucidation and panacea to ongoing sexuality conflict.

Essentially, the article argues that, by focusing on sexual orientation and identity conflict nexus in construction of social reality, there is need to directly engage with the persistent challenges of the conflicts in the United States which has claimed several lives and invariably disrupts social harmony and affects peaceful co-existence of the LGBTQIs and non LGBTQIs. This research aims to filling this gap and address the challenges of sexual orientation identity conflict. In what follows, the paper will present the theoretical framework and research methodology, evidence of perverse rise in sexual orientation conflict in the US, data analysis, conclusion and recommendations.

\section{Theoretical Framework AND Methodology}

Two theoretical models are explored in this study. First is the conflict theory. According to John Galtung (2009) conflict is an incompatibility of goals. Thus, the article examines sexual orientation identity conflict within the context of incompatibility of sexuality goals between the LGBTs and the non LGBTs. It explores the depth of the conflict and how it could be resolved.

Next is the green sexuality framework which posits that sexual intercourse is an intercourse between the opposite sexes. It protects the sexual needs of the present partners and the natural environment without compromising the ability of future generations from meeting their own sexuality needs (Amadi and Wordu, 2016).This work builds on these frameworks and argues that despite the increasing conflicts on the basis of sexual identity and orientation, the plausible option is a novel collective re-engagement to uphold the tenets of preserving the sexual needs of both the present and the future generation. This is premised on conventional straight intercourse informed by the primacy of procreation and respect for the dignity of human sexuality (Amadi and Wordu, 2016).

Regarding the methodology, this research is a longitudinal field survey conducted between1990 to 2015 to provide robust evidence of sexual identity conflict. Primary data collection involved a participatory methodology which included virtual online surveys on adult males and females between the ages of 25 to 50 which was conducted among gay and non- gay communities in New York City, it included LGBT based NGOs, LGBT movements and Community Based Organizations (CBOs), 
Christians and non- Christians .Majority of the participants (75\%) were drawn from (CBOs) and 25\% from LGBT based NGOs and movements. Participants were deployed between August 1999 and January 2000, supplementary surveys were conducted between September 2014 and December 2015.Among the 300 respondents, seven were ineligible, three provided invalid data, while two were duplicate data. A total of twelve was rejected. The final sample had 228 participants $-60 \%$ male and $40 \%$ female. Each participant produced voluntary information as questionnaire was virtually administered.

Secondary data included relevant previous researches, books, reports, internet materials and seminars. The measurement of sexual identity conflict was conducted using the Sexual Identity Conflict Assessment - Adult (SEICO-A) a model developed in this study for LGBT and non LGBTs to measure specific items. It builds on Munter (1976), Lucente (1996) and Field Survey,(2015).It is composed of six items namely sexual orientation, perception on homosexuality, tolerance of homosexuality, willingness of disclosure of sexual orientation, experience of hate crimes, the general social desirability of self- sexual identity.

The Confluence Model of Sexual Aggression (Malamuth, 1995) was equally explored. Also relevant seminal debates and literature regarding SEICO-A were examined. A single item from the SEICO-A assessed sexual identity conflict at every assessment period among participants such as homophobic bullying(Rivers,2011).Equally, Munter (1976) identified sexual identity conflicts among children and adults and contends that it has been inherent in reshaping subsequent sexual behaviors.

Similarly, items related to sexual orientation were also constructed within the SEICO-A model to identify sexual aptitudes, interests and inclinations of participants. Including sexual preferences and habits.

In a multidisciplinary and multi-institutional assessment of "sexual minority" on the basis of "people who are attracted to or have had experience with same-sex partners, or someone who identifies as lesbian, gay, or bisexual" , the 2009 Sexual Orientation Survey conducted by the Sexual Minority Assessment Research Team (SMART), explored sexual orientation from three major dimensions; "Self-identification: how one identifies one's sexual orientation (gay, lesbian, bisexual, or heterosexual) .Sexual behavior: the sex of sex partners (i.e. individuals of the same sex, different sex, or both sexes).Sexual attraction: the sex or gender of individuals that someone feels attracted to". Participants were asked their foremost attraction to same sexes, initial development of such erotic desires and the first time they had such intercourse. Bogaert (2000:361) defined sexual orientation as "the erotic inclination or attraction for the opposite sex (heterosexuality), the same sex (homo sexuality), or both sexes (bisexuality)".

The items identified and the experiences of the LGBTs in the context of assault/violent attacks and discrimination were computed specifically from 1990 to 2016.Participants were asked about the first day they had the experience of any form of discrimination, stigmatization or attack on the basis of sexual orientation-homosexuality or bisexuality. They were asked to share some outdoor social experiences either as LGBTs or non LGBTs in the context of employment, social work, holding of public office, interactions with the wider society in public life such as membership of organizations, social clubs, employment, political or religious offices and in particular on the basis of same sex marriage.

They were asked to explain any experience of hate crime on the basis of sexual orientation. The information was used to compute the period at which the participants were discriminated either in the pre or post- Cold War era and in particular, the intensity and forms of such discrimination. Similar investigations pointing out sexual orientation discrimination were examined to further elucidate incidence of stigmatization, hate crimes and discrimination on basis of sexual orientation (FBI, 2004; Stotzer, 2007; Herek, 2009).

Participants were engaged in more direct questions on their current sexual orientation-This builds on the sexual orientation grid (Klein et al.; 1985). Thus, the SEICO-A model was used to assess more critical dimensions current sexual orientation have taken in the contemporary neo liberal order by deploying three key dimensions from SMART already explicated. Participants were asked questions based on most recent trends and changes in the ongoing sexuality conflict debate. Including their perceptions on legalization of SSM in the United States. Similar literature suggestive of dynamics of current sexual orientation was examined (Klein et al; 1985; Sell, 1997; Carpenter, 2005; Russell and Joyner, 2001; Bogaert, 2000). 
Participants were required to explain the extent their sexual attractions had caused them physical assault, injuries and stigmatization using A 7-point Likert response scale.

General attitudes toward homosexuality was examined-About 20 items which built on Rosario (2006) , Throckmorton, (2006) and (Nungesser, 1983) were adapted for participants using a 6- point response scale encompassing "true/false" agree", "disagree", "yes/no" items.

Compatibility with homosexuality (Eldridge, et al; 2006) was explored specifically in rural and urban America 6 point response scale was deployed and constructed within "yes" and "no" items. willingness of disclosure of sexual orientation was conducted using Rosarios' self -identity development scale (Rosario, 2006) as well as the internalized homophobic scale in relation to attitudes and Stages of development - Participants were asked to explain the people they disclosed their sexual identity to and possible implications such as attacks or hate crimes. The indication was positive and reflective of strong believe in their sexual identities and followed by massive evidence of stigmatization by non LGBTs.

The general social desirability of their sexual orientation identity was explored using the MarloweCrowne Social Desirability Scale (Crowne \& Marlowe, 1960). This indicated that most non LGBTs termed the LGBTs and their sexual orientation as socially undesirable (See Catholic Bishops Conference,2013;Schaefer,2013). The study findings are mitigated by potential limitations. First, our sample was recruited from both gay and non-gay-focused organizations and communities, therefore, the extent to which the findings generalize to a more heterogeneous sample of sexual orientation identity conflict seem unknown. However, our theoretical literature through a relational content analysis and existing research in the field provided additional valid data. So the present research does not consider that a major limitation. Also the size of the sample and the targeted participants were suitable and provided sufficient data to distinguish a novel contribution of the research agenda over previous studies in the subject.

Equally, the entire participants in this study both gays and straight were followed up timely for two years. This was aimed at understanding possible (if any) changes in their sexual orientation and level of consistency over time. Our data, though limited to a two-year follow-up period, the fifteen years period of study (1990 to 2015) lend further insights and credence to the understanding of sexual orientation identity conflict.

\section{Exploring Evidence of Persistent Sexual Orientation Identity Conflict}

Studies in sociology of sexual orientation conflict had taken several dimensions including the deviant behavior thesis which contends that SSM is considered a deviant behavior hence perverse attacks on the LGBTs (Schaefer, 2013). William Eskridge( 1993) argues that classical antiquity in the Western world is often quoted as instances of same-sex love and relationships, that distinct concepts of homosexuality and heterosexuality never existed as they are today .

In the present context, sexual orientation identity is a deeply racialized concept, which masked imperial relations to the same extent as it celebrated the racial diversity of the United States. As the social construction of reality changed following the liberal order, sexual orientation equally changed .The long 'oppressed' LGBT community re-emerged in public and social circles. The realm of policy, social, cultural and academic research began to reflect these new changes. Manuel Castells (2000) conceptualized this within the realm of the "new society" encapsulated within the network states. Within this technological construct, sexual orientation equally acquired a globalized image including online sexual intercourse of gays and lesbians. Distinctively, the building of online sexual alliances and LGBT networks blossomed and was opened to a number of opposition and attacks.

In a distinct manner, sexual orientation identity conflict takes a number of dimensions. Accordingly, Herek (2009, p.3) shows that sexual stigma is a key strand of sexuality crisis that defines sexual minorities in relation to their interaction and identity with the wider society. Within religious conflict dynamics, there are evidence of resilience on moral grounds. For instance, the case of a Christian and staff of Kentucky County Clerk, Kim Davies vs the Local Court is insightful on sexuality conflict dynamics. In August 2015 in Kentucky, despite the legalization of SSM by the United States supreme court, Kim Davis, a female Kentucky County Clerk remained supportive of the non- issuance of marriage certificates to gay couples and argued that; "to issue a marriage license which conflicts with God's definition of marriage, with my name affixed to the certificate, would violate my conscience. It 
is not a light issue for me. It is a Heaven or Hell decision" (Galoforo,2015, p.1).A similar account from the religious perspective is recorded from the Catholic Bishops Statement (2013,p.2) which recounts that the union of same-sex is not "uniquely complementary, mutually loving, and procreative relationship that God intends marriage to be as reflected in the way he created human nature" .

The psychological debate espouses "sexual aggression". For instance, Archer (2004) provides a metaanalysis exploring aggression in sex differences in real life situation. This points to the perverse discrimination, attacks and assaults on the basis of sexual identity and orientation. There is evidence of targeted attacks and killings which suggest the intensity of the ongoing conflict. In a 2011 study, built on two decades of human rights patterns, the United Nations High Commissioner for Human Rights found that "76 countries criminalize adult same-sex consensual relationships". The findings further suggested that discrimination within States on the basis of sexual orientation identity in the public sector services included education, workplace and health sectors. Again, that there is prevalence of hate induced violence against LGBT people in various regions, which include sexual violence, physical assault and targeted killings. That the attacks are not limited to these dimensions (Sklar, 2013).

In the United States, there are a number of evidence which point to the prevalence of sexual identity conflict. The data for this study derive from extensive fieldwork in the United States, which at the same time helps to illuminate recent broader issues and on the ground evidence associated with sexual identity conflicts. To critically explore the novel turn these conflicts had taken since the rise of liberal democracy is symbolic for scholars seeking for an understanding of the intensity of the violent conflicts and failures of the Western liberal Democracy project to sustainably ameliorate the perverse conflicts. The dominant punitive measure which is jail term for alleged culprits is both ineffectual and non-responsive to the understanding of the complexities of sexual identity orientation conflicts.

In the 1990s, as liberal democracy brought novel freedom to individuals and groups, the issue of sexual orientation came to the fore. The divergent nature of sexual identity and orientation became perceptible by different groups and individuals.

In addition, global LGBT alliances and networks began to nest their solidarity which in turn had a powerful impact upon the legalization of gay marriage Sexual right which was perceived as human right was legalized .This perhaps was contradictory at some point both within sexuality constructs and wider social milieu. Such legal rendition rather than abate sexuality conflict perhaps exacerbated it.

Distinctly, between 1990 to 2016 as liberal democracy takes tool, evidence of perverse killings on the basis of sexual orientation became a common place as social representative institutions and movements gained scope and authority. US LGBT community found through the liberal currents a paraphernalia for vigorous opposition to the dominant notion of social discrimination associated with their sexual orientation. Liberal democracy was thus a protagonist of equality forces, including sexual equality. Yet this required the exertion of novel engagement to be actualized. Including recreating the notion of the non LGBTs how LGBT is a conventional sexual orientation or otherwise.

However discourses of revolutionary transformation and resurgent LGBT movements notwithstanding, the actual agenda of non LGBTs could be seen as institutionalization of LGBT free society. This notion is most palpably linked to the novel turn sexual identity conflicts had taken since the return to liberal democracy in 1990.For instance, a recent report suggests that the 2016 killings in Orlanda Florida, was the highest mass killing in the United States and the nation's worst terror attack since 9/11 (Ralph Ellis, Ashley Fantz, Faith Karimi and Eliott McLaughlin, 2016). Above all, the failure of the institutional punitive measures notably, jail terms to resolve the conflict points to a critical policy and research re-engagement.

As sexuality conflict gradually gained relevance, its perverse occurrences have been less studied .On June 16, 2001, Gerstenfeld (2004)argued that 18-year-old Shaun Murphy, attacked and beat to death Fred Martinez, a transgender student in Cortez, Colorado. The December 2002 murder in Philadelphia ,Pennsylvania of Nizah Morris, a 47-year-old black trans woman was indicative of the persistent attacks( Fenner and Weir,2002). Again, on December 12, 2001 another attack was recorded in Florida as Terrianne Summers, a 51-year-old trans woman and activist for transgender rights, was shot and killed in her front yard. On May 11, 2003 there was a related experience at Newark, New Jersey in which Sakia Gunn, a black 15-year-old lesbian, was murdered while waiting to board a bus (Ronald, 2004). 
On June 17, 2003 Richie Phillips of Elizabethtown, Kentucky was killed by Joseph Cottrell because he was gay (Inquirer,2003).A related occurrence was witnessed on August 2003in which a new analysis finds Washington, D.C. topping the list in transgender murders as YusefNajafi (2006)argued that following the murder of a black 25-year-old trans woman, Emonie Spaulding who was shot dead in Washington DC by Derrick Antwan Lewis after he discovered she was trans. In Waverly, Jafari, Samira (2004), reports that in Ohio on July 22, 2004 18-year-old Scotty Joe Weaver of Bay Minette, Alabama, was murdered.

Similar experiences occurred in Detroit and Iowa between 2005 and 2007. In March 11 2005, Jason Gage, an openly gay man, was murdered in his Waterloo, Iowa, apartment by an assailant, Joseph Lawrence, who claimed Gage had made sexual advance to him (International Centre for Advocates Against Discrimination, 2005), This was less compared to what was in stock in subsequent years .Between 2006 to 2015 it was evident that despite jail term to culprits, sexuality conflict had gone out of hand in the United States. For instance, Barbara Wilcox(2007)reports that in February 27,2007, Andrew Anthos, a 72-year-old disabled gay man, was beaten with a lead pipe in Detroit, Michigan by a man who was shouting anti-gay names at him. Anthos died 10 days later in the hospital.

Paddock, Barry, Jess Wisloski and Tina Moore (2008), report that on February 10, 2008, Sanesha Stewart, a 25-year-old black trans woman was stabbed to death in Bronx, New York.The Carolina and Illinois experiences, where sexual orientation identity induced attacks resulted in serial killings were not different. According to Cormer(2010),on April 3, 2010, Toni Alston, a black 44-year-old transgender woman, was shot in the front door of her home in West Charlotte, North Carolina. Equally, Emmanuel Adeshina (2012), argued that on April 21,2012, Eric Unger, a 23-year-old gay man living in Illinois, was attacked by a group of men on the way home from a party, while they shouted anti-gay epithets at him .On May 17 2013,Mark Carson, a 32-year old black gay man, was shot to death by another man who trailed and taunted him and a friend as they walked down the street in Greenwich Village, New York (Slattery, 2013).On February1st 2015 incident ,TajaDeJesus, 36, a trans woman of color, was found stabbed to death in the Bayview neighborhood of San Francisco, California( Williams, 2015 ). In Orlanda Florida, Omar Mateen, 29 gunned down 49 people early Sunday at a gay nightclub in Orlando, the deadliest mass shooting in the United States and the nation's worst terror attack since 9/11 (Ralph Ellis, Ashley Fantz, Faith Karimi and Eliott McLaughlin,2016). These violent attacks and killings point to urgency of new intervention.

\section{DiscuSSIONS}

Between 1990 to 2016, sexual orientation identity attacks had taken several lives. At the instance of these disasters, jail term which was the dominant punitive measure appeared ineffectual as it has never mitigated the perverse conflict.For instance, the eddies of the violent attacks continued in 2011 to 2016 in virtually every neighborhood in the United States. The complexity of these attacks and the often confounding circumstances call for further critical research and policy framings. In a particular instance such as the 2016 Orlando shootings which was the highest in the history of gay attacks in the United States, recorded about 49 deaths. This representation of the United States spiraling downward into a maelstrom of uncontrollable disorder achieved popular currency through the persistent assault on the LGBTs in almost three decades of the liberal order .Are these not influential pointer that the liberal order has not fared well in sustainably resolving sexual identity orientation conflicts?. Alternative measures are inevitable. Thus, the notion of freedom of assaults, discrimination and attacks guaranteed in a liberal order remains in doubt at a time revaluing sexuality conflict.

The findings from the data generated suggest that these persistent attacks on the LGBTs by non LGBTs on the basis of their sexual orientation took several dimensions. The SEICO-A model and the items therein which were compared and summarized threw more light in this direction. The aim of the SEICO-A model was for an independent understanding of unit variables involved in sexual orientation identity conflict analysis. These were considered to be relevant in understanding dynamics of contemporary sexual identity conflict. This was reinforced in the field analysis conducted during the study which correlates each SEICO-A item with reports of the participants to the questionnaires which were significant at the .05 level or below. Thus, the field analysis was consistent with the use of the SEICO-A model in rating and exploring both sexuality identity perspectives among the respondents and their perception of sexual identity conflicts. 
Sequel to the related data from the relevant literature, the persistence sexual orientation identity conflict was further corroborated (see for example Munter, 1976; Miller and Ryan, 2011, Amadi and Wordu, 2016). There are similar seminal data such as the United States FBI data which in 2004, showed that $15.6 \%$ of hate crimes recounted by the police were linked to sexual orientation. $61 \%$ of the assaults were at gay men, 14\% against lesbians, $2 \%$ against heterosexuals and $1 \%$ against bisexuals, while attacks against LGBT people at large made up 20\% (FBI,2004).In 2006, the FBI report shows that attacks on gays increased from $14 \%$ to $16 \%$ in 2005 , as overall percentage hate crimes across the U.S.(FBI,2007)..The 2006 annual report, which came out on November 19, 2007, equally revealed that hate crimes based on sexual orientation are the third most common next to race and religion (FBI, 2007).

In 2008, $17.6 \%$ of hate crimes were based on the victim's perceived sexual orientation. Of those crimes, $72.23 \%$ were violent in nature. 4,704 crimes were committed due to racial bias and 1,617 were committed due to sexual orientation. Of these, only one murder and one forcible rape were committed due to racial bias, whereas five murders and six rapes were committed based on sexual orientation (FBI, 2008).

In 2011, the FBI reported 1,572 hate crime victims targeted based on a sexual orientation bias, making up $20.4 \%$ of the total hate crimes for that year. Of the total victims, $56.7 \%$ were targeted based on anti-male homosexual bias, 29.6\% were targeted based on anti-homosexual bias, and $11.1 \%$ were targeted based on anti-female homosexual bias (FBI, 2013).

\section{CONCluSion}

The last three decades or so has seen the rise of sexual orientation conflict in the United States contrary to expectations that the liberal order will douse such conflicts. The persistent targeted attacks and killings suggest that the inner core of liberalism was, in contrast, even though for several decades, the United States had clamored for a pivotal roles in various spheres of human endeavor, the ineffectual policy response to mitigate sexual identity conflict requires urgent policy attention. The rise in dominant rivalry of public sphere of the LGBTs and non -LGBTs often points to the notion of "contested liberalism", if it is viewed from the point of view of protecting the minority rights, the morality component of liberalism remains in doubt. Liberal democracy cannot thrive in moral bankruptcy-a tendency which seems less naturalized in the core of American lifestyle. Equally, the rude brutality and torture linked to LGBT attacks lacks moral undertone. The question for something more distinct is critical. There have been and still remains ample doubt that the legalization of SSM could in anyway bring an end to discrimination on the basis of sexual orientation. The entire line of debate in this research perhaps suggests the failure of the neo liberal order to provide amenable and inclusive strategy that could douse sexuality conflict. The increasing incidence of sexual orientation motivated violent attacks despite the Equality Act (Sexual Orientation) Regulations of 2007 which prohibits discrimination on the grounds of sexual orientation by the US government in 2015 reveal the perverse turn sexuality conflict had taken in recent times.

At the human level, sustainable sexuality is pro human, pro nature and green to the extent that it involves both sexes and by extension promotes equality (Amadi and Wordu, 2016). For example, a feminist who responded to our interview was passionate about marital values and contended that women invariably are at the receiving end in same sex marriage and intercourse as most of them who would have wished to get married as straight couples and raise children run the risk of having such chances truncated.

The data by the FBI suggest evidence of persistent discrimination, attacks and killings by the nonLGBTs while the LGBTs clamor for protection and preservation of their sexual rights as they remained consistent with their sexual identity and orientation. The society's awareness on sustainable human development is critical to the understanding of the long term implications of legalization of SSM. Humanistic debates detest the killing of humans on the basis of sexual orientation, it also conceives "Man Sex Man (MSM) and Woman Sex Woman (WSW)" (Amadi and Wordu, 2016) as amoral. The debates on sexuality conflict have not provided a cutting edge policy that critically engages the future of human development. The present research and its findings reveal that the novel propagation of same sex marriage within the legal parlance partly accounts for the resurgence of sexual identity conflict. 
Such critical prognosis goes beyond legalization, human rights or sympathy for the LGBTQIs. More rational and pragmatic policy discourse is expedient particularly in sustainable human development contexts. In the contemporary order this appears to be at odds in lieu of same sex marriage.

To construct a new self-orientation toward protecting and preserving human species is important. This opens to discussions on sexuality and sustainable human development linked to concepts such as green sexuality (Amadi and Wordu, 2016). Robert Goodland (1995), shows that implementing sustainability encompasses putting economic, social and environmental practices to work. By integrating sustainability, the societies connect the actions and promote personal involvement mostly in interaction with nature.

While the non LGBTQIs on their part seem averse to the sexual orientation of the LGBTQIs as demonstrated. This identity conflict could be hugely significant and very critical for a more global inclusive and re-integrative policy response. The mainstreaming of sexuality conflict resolution into the wider international policy response has not been effectively captured in global and local governance. LGBTQIs remain entangled with various social trauma such as stigmatization, job discrimination, social services and attacks faced in the hands of non LGBTQIs. The debate surrounding LGBTQIs transformation has been largely marred by political, sectional and social interests. There is evidence of highly contradictory perspectives and varying agenda especially the class of highly placed businessmen and top politicians involved in the homosexuality, a more committed strategy of transformation seems difficult.

Similarly, normative influences such as religious, cultural and moral debates largely account for persistent stigmatization of the LGBTQIs as explicated. International actors, NGOs, social workers, the civil society organizations (CSOs)- FBOs and CBOs could collaborate to contrive strategies to resolve and integrate the ongoing sexuality conflict resolution into the day-to-day interactions of the society. The present research addresses the existential realities of both the LGBTQIs and non LGBTQIs to recreate and realign their differences by suggesting the possible strategies to contend the prevailing sexual identity conflict.

This includes the debate on redefining human sexuality in the neo liberal order. What is sexuality?. Sexuality in its current state is conflictual. For society to adopt and promote a unique, socially amenable and popular standards of, distinctive, and enduring identity, do we need to redefine human sexuality?.

Can a new world for the LGBTQIs be created?. The possibility of such policy question is both critical and contradictory. That is, a distinct world that could promote uninterrupted existential realities of the LGBTQIs and in particular, meet their emotional needs?. And possibly end sexuality conflict?. There are arguments by functionalist theorists which largely conceive such intercourse as a deviant behavior and has no value to the wider human society (Schaefer, 2013).Also similar discrimination is experienced in non- Western societies of the Third World and makes the problem a rather universal concern.

Mediation and social harmony should be institutionalized as key strands of value re-orientation and emancipation of both the LGBTQIs and non LGBTQIs. In particular, the opposition to same sex marriage by non-Western societies are issues of increasing global policy concern and opens this agenda to further research. More constructive patterns of legislation require closer matches between legal pronouncements and long term effects. It is understandable that liberalism is rooted in freedom, there are contestations, dissonance and conflicts riddled in contemporary sexuality. How to resolve these conflicts are of particular concern to this study and opened to future research. Wakefield (2003) contends whether sexual reorientation is ethical and beyond that argues whether it could effect changes in sexual motivations, which are critical issues of policy discourse. However beyond what ever strand or perspective, the rehabilitation debate has been seminal as same sex intercourse is at variance to conventional notion of human sexuality conceived by sociologists as a social construct which could equally be alleviated through social instrumentalities.

Thus, sexuality conflict as explicated is both ideological, social, political and psychological and involves a wide range of issues outside the immediate confines of the Western societies. Novel policy and global forum to discuss what sexuality should mean in the neo liberal order is critical. 


\section{REFERENCES}

Adeshina E .(2012). "Gay student claims hate attack in beating at Illinois State University". Chicago Sun-Times. Retrieved https://scottiestoybox.com/2012/04/22/gay-student-claims hate-attack-inbeating-at-illinois-state-university-chicago-sun-times.

Amadi L and Wordu,S (2016). The clash of sexuality or rhetoric of human rights: Exploring same sex marriage and sustainable human development nexus International Journal of Peace and Development Studies Vol.7(1), pp. 1-14

Ames P (2013). - Dutch gays don't take advantage of opportunity to marryll Available at http://www.globalpost.com/dispatch/news/regions/europe/benelux/110419/netherlands-gayrights-same-sex-marriage

Archer, J (2004)."Sex differences in aggression in real-world settings: A meta-analytic review." Review of General Psychology $8: 291-322$.

Comer M .(2010).Info sought in Charlotte transgender murder Investigators working with community, looking into victim's correspondence.

Denis S (2013). "Gunman shoots 32-year-old Mark Carson dead in Greenwich Village bias attack: officials". New York Daily News

Ellis R, Fantz A, Karimi F and McLaughlin,E ( 2016) Orlando shooting: 49 killed, shooter pledged ISIS allegiance CNN News Accessed http://edition.cnn.com/2016/06/12/us/orlando-nightclubshooting/.

Eskridge Jr.,W (1993) A History of Same Sex Marriage79 Va. L. Rev. 1419

Bogaert, A. (2000). Birth order and sexual orientation in a national probability sample. Journal of Sex Research, 37(4), 361- 368.

Brundtland Report (1987). Our Common Future. Oxford Press

Catholic Bishops Statement (2013). - Human Sexuality, Marriage and Same-Sex Unionsll Chapter 1: Theoretical Background (pp. 3-34) and Chapter: 14: Normative Orientations toward Sexuality pp. 509-540. Available at: http://www.pacatholic.org/bishops-statements/human-sexualitymarriage-and-same-sex-unions/\#sthash.YEuOsTU1.dpuf

Carpenter C(2005).“Women, Children and Other Vulnerable Groups”: Gender, Strategic Frames and the Protection of Civilians as a Transnational Issue International Studies Quarterly

Crowne D, Marlowe D. (1960) The approval motive: Studies in evaluative dependence. Westport, CT: Greenwood.

Dutton, D, and White K. (2013).“Male victims of domestic violence.” New Male Studies International Journal $2: 5-17$.

Eldridge V , Mack L \& Swank E Explaining Comfort with Homosexuality in Rural America Journal of Homosexuality Volume 51, Issue 2 pp 39-56 .

Foucault, M (1980). The History of Sexuality, Volume I. Vintage.

FBI, (2004)."Hate Crime - Crime in the United States 2004". Federal Bureau of Investigation.

FBI ,2007) "FBI Shows Gay-Bashing Increase in 2006". The Advocate. November 20, 2007. Retrieved November 25, 2007.

FBI, (2008).Hate Crime Statistics: Offense Type by Bias Motivation". Federal Bureau of Investigation. 2008.

FBI (2011) - Victims". fbi.gov. Retrieved from www fbigov about us -cjis-ucr-hatecrie -2011narratives-victis Retrieved July 2014.

Fenner A and Weir R (2002) "GRISLY MURDER IN BX. Hair stylist stabbed 43 times in bathtub". New York: NY Daily News. August 6, Retrieved from http://www.nydailynews.com/ archives/news/grisly-murder-bx-hair-stylist-stabbed-43-times-bathtub-article-1.507576

Galofaro C“Clerk citing 'God's authority' over high court on gay marriage to face judge” April, 2015, Associated Press.

Gerstenfeld, P (2004). Hate Crimes: Causes, Controls, and Controversies. SAGE. pp.1, 293.

Giddens, A.(1992). "Foucault on Sexuality" in The Transformation of Intimacy: Sexuality, Love and Eroticism in Modern Societies. Stanford CA: Stanford University Press. 
Goodland, R. (1995). The concept of environmental sustainability. Annual Review of Ecology Systematics, 26(1): 1-24

Hall S and du Gay P (1996), Questions of Cultural Identity London: Sage

Haseldon L and Joloza T(2009).Measuring sexual identity A guide for researchers. Household, Labour Market and Social Wellbeing Division Office for National Statistics Government Buildings Cardiff Road Newport NP10 8XG.

Herek, G.. (2009). Sexual stigma and sexual prejudice in the United States: A conceptual framework. In D. A. Hope (Ed.), Nebraska Symposium on Motivation: Vol. 54: Contemporary perspectives on lesbian, gay, and bisexual identities (pp.65-111). New York: Springer.

International Centre for Advocates Against Discrimination,(2005)Retrieved https:// icaad.ngo/ hatecrimes-in-the us/?gclid=Cj0KEQiAgJTGBRDLr5_az_Ouk44BEiQAIxaA4hzmuqiZypnoNzrbUWzW6340HY NPrIAQ355Bmfs5oJUaAsU58P8HAQ.

Jafari, S (2004), "Killing of gay teen raises issue of intolerance in state", Associated Press.

Klein, F, Barry S, Wolf, T. (1985). Sexual orientation: A multivariable dynamic process. Journal of Homosexuality. 11, 35-49.

Lucente R - (1996). Sexual identity: Conflict and confusion in a male adolescent Child and Adolescent Social Work Journal. Volume 13, Number 2.

Malamuth N Daniel Linz,Christopher L heavey.Gordon Barnes Michele Acker(1995) Using the Confluence Model of Sexual Aggression to predict men's Conflict with Women: A 10 -year Follow -Up Study Journal of personality and Social Psychology Vol.69 No.2,353-369

Miller, K., \& Ryan, M. J. (2011). Design, Development and Testing of the NHIS Sexual Identity Question:National Center for Health Statistics.

Müser K (2012). - Youth negotiate future of human rights in Europell Available at http://www.dw.de/youth-negotiate-future-of-human-rights-in-europe/a-16441819 Accessed $10 / 2 / 2014$.

National Inquirer (2003). "Family of murder suspect speak out". National Enquirerhttp://www. enquirer.com /editions/2003/08/27/loc_kysuitcasebody27.html

Najafi Y (2006) .Transgender Tragedies A new analysis finds Washington, D.C. topping the list in transgender murders Metroweekly Retrieved http:// www.metroweekly.com/ 2006/12/ transgender-tragedies/

Nungesser L.(1983) .Homosexual acts, actors, and identities. New York: Praeger.

Paddock, B; Wisloski, J, Moore T .( 2008). "Slain transgendered neighbor 'a friend of whole building,' Bronx man says". New York Daily News. http://www.nydailynews.com/news/ny_crime/ 2008/ 02/11/2008-02

Rivers, I. (2011). Homophobic bullying: Research and theoretical perspectives. New York: Oxford

Rosario, M, Schrimshaw, E, Hunter J, and Braun L (2006), Sexual Identity Development among Gay, Lesbian, and Bisexual Youths: Consistency and Change Over Time J Sex Res. 43(1): 46-58.

Russell, S and Joyner K (2001); Adolescent Sexual Orientation and Suicide Risk: Evidence From a National StudyAmerican J Public Health; 91(8): 1276-1281.

Schaefer R (2013). Sociology Matters, McGraw-Hill

Schofield M (2013). Europe's image of tolerance doesn't extend to gay rightsll. Available at http://www.mcclatchydc.com/2013/07/16/196832/europes-image-of-tolerancedoesnt.html\#storylink=cpy

Sell, R. (1997). Defining and measuring sexual orientation: A review. Archives of Sexual Behavior. 26(6), 643-658.

Sklar R (2013). - -High-Level Meeting on Role of United Nations to End Violence and Discrimination against LGBT People\|l 09/26/2013 Available at http://article.wn.com/view/ 2013/09/26/ HighLevel_Meeting_on_Role_of_United_Nations_to_End_Violence

Smothers, R (2004). "Newark Preaches Tolerance of Gays Year After Killing". The New York Times. 
Storey, J, and Strand S.(2012). "The characteristics and violence risk management of women arrested by the police for intimate partner violence." European Journal of Criminology 9636-51.

Stotzer, R. (2007). Comparison of Hate Crime Rates Across Protected and Unprotected Groups, Williams Institute.

Tregenza T, Wedell N and Chapman T(2006) .Introduction. Sexual conflict: a new paradigm? Phil. Trans. R. Soc. B ,361, 229-234

Throckmorton W, and Yarhouse,M.(2006) .Sexual identity therapy: Practice framework for managing sexual identity conflicts

Wakefield, J. (2003). Sexual reorientation therapy: Is it ever ethical? Can it ever change sexual orientation?Archives of Sexual Behavior, 32, 457-461.

West, C and Zimmerman D (1987)."Doing Gender." Gender \& Society 1 : 125-51

Williams K.( 2015). Family mourns transgender woman fatally stabbed in San Francisco Retrieved from http://www.sfgate.com/crime/article/Family-mourns-transgender-woman-fatally-stabbed6067154.php

Wilcox,B (2007). Sketch released of suspect in Detroit gay bashing The Advocate Retrieved http://www.advocate.com/news/2007/03/02/sketch-released-suspect-detroit-gay-bashing. 